\title{
Analysis of the Development Prospect of Internet Auto Insurance
}

\author{
Xinggang Huang \\ School of Finance \\ Zhongnan University of Economics and Law \\ Wuhan, China 430073
}

\begin{abstract}
The rise of mobile Internet has attracted a large number of traditional industries to be closely integrated with it, including insurance industry. Internet auto insurance is the perfect combination of Internet and traditional insurance products. As a kind of insurance with high degree of standardization in property insurance, auto insurance has a high Internet penetration rate. This paper analyzes the comparative advantages of Internet auto insurance in the three aspects of channel entrance, product pricing and product innovation, and analyzes the existing problems of Internet auto insurance.
\end{abstract}

\section{Keywords - auto insurance; Internet; development prospect}

\section{INTRODUCTION}

The emergence of Internet auto insurance has solved the problems of sluggish development, high operating cost and poor user experience of China's traditional auto insurance industry. Favored by many car owners, the Internet auto insurance in China has a promising development trend and huge development potential. However, compared with the Internet insurance business in developed countries, there is still a certain gap. Therefore, Internet auto insurance business has become the focus of increasing attention of major insurance companies, and the development of Internet auto insurance business has become a major development strategy of the company.

Based on the big platform of the Internet, the Internet auto insurance carries out comprehensive transformation of auto insurance, so as to realize the deep integration of auto insurance and the Internet. The essence of Internet auto insurance is to put all the links of including insurance, survey and claims, etc. on the Internet, by use of the transparency, low cost of information transmission and other characteristics of the Internet so as to let the technology of Internet apply to every link of auto insurance comprehensively. In this way, the connection between the insured customers and the insurance company is closer and the communication is more effective, and the insurance company returns to their basic functions of developing and designing better insurance products, dedicating itself to the quality of insurance claim service, and allowing the car owners to really buy auto insurance according to their needs, or even customize the auto insurance.

\section{COMPARATIVE ADVANTAGES AND EXISTING PROBLEMS OF INTERNET AUTO INSURANCE BUSINESS}

\section{A. Comparative Advantages of Internet Auto Insurance Business}

The Internet is characterized by open framework, humancentered management and human-human interactive communication, through which it gradually infiltrates into traditional industries. This is especially true in the era of mobile Internet. Business model changes rapidly with the change of technology, consumer groups and consumer behaviors.

1) Advantages in channel entrance: Internet auto insurance mainly sells their products through relevant Internet platforms. Different from the traditional mode of auto insurance mainly relying on $4 \mathrm{~s}$ shops and other intermediary organizations to sell, it will have a profound impact on the sales of automobile insurance. The Internet features high speed and large capacity of information transmission. The combination of auto insurance and Internet can make it more convenient for auto insurance buyers to obtain relevant information of auto insurance. In addition, the consumption of human resources and time in the process of information transmission can be reduced to avoid the high input and low output in the link of information transmission, and greatly reduce the selling cost of insurance companies. Meanwhile, the openness of the Internet allows buyers to search for auto insurance products of different property insurance companies on the Internet and get the introduction of relevant products and relevant terms. Therefore, the phenomenon of sales misleading caused by marketing personnel under the circumstance of traditional marketing is avoided. Also, the insurance buyers can consult online and shop around so as to buy the insurance that they are satisfied with.

With the gradual development of the Internet, the application of big data can make products more targeted. In the field of Internet auto insurance sales, the application of big data can help insurance companies accurately analyze the preferences and characteristics of each auto insurance buyer and their suitable auto insurance products, and sell 
personalized insurance to meet the different consumption needs of each buyer, so as to achieve precision marketing.

With the increasing competition in the insurance industry, the establishment of marketing channels has been paid more attention to by insurance companies. The internet auto insurance business can be carried out through the Internet platform built by insurance companies. By selling auto insurance through the self-built online sales platform, insurance companies can control a large number of highquality customers in their own hands through high-quality services, and do not have to spend a lot of money to rely on intermediaries, so that the initiative is in the hands of insurance companies themselves.

2) Advantages in product innovation: In the Internet era, the application of network means and platform enables the in-depth integration of traditional auto insurance and Internet, providing an excellent opportunity for insurance innovation. It is feasible to make in-depth integration of characteristics of the Internet and insurance products and apply Internet platform, cloud computing, big data and other advanced Internet technologies to insurance products to promote the research and development of insurance products and produce a large number of innovative insurance products.

Insurance companies' exploration of the Internet is just not limited to transferring offline insurance products to online sales, but more to the deeper cooperation between the Internet and insurance. For example, aiming at the real-time and convenient characteristics of the Internet, Zhongan Insurance launched jointly with Taobao "Zhonglebao", the first innovative Internet insurance product developed in the field of e-commerce. It is mainly targeted at sellers in Taobao Marketplace, and has carried out comprehensive innovation in claims settlement, pricing, responsibility scope and other aspects, so as to support the entrepreneurship of small and micro enterprises.

As a kind of insurance with high degree of standardization, auto insurance is more likely to produce more innovations when combined with the Internet. For example, UBI auto insurance was developed by Nanjing Renren Insurance Network Technology Co. Ltd and Dubon Insurance, and hardware data acquisition was completed by on-board OBD. It can record the driving time, driving distance and driving track of the owner, as well as the driving habits and other logical calculations, and then calculate the insurance charges to be paid. This solves the problem of "reverse subsidy" caused by the unfair collection of auto insurance premium, which makes the car owners with low mileage and low risk subsidize the car owners with high risk and high mileage.

3) Advantages in product pricing: The advantages of Internet auto insurance pricing are mainly reflected in two aspects. On the one hand, sales through the Internet platform can save the link of intermediaries and the promotion with a large amount of human and material resources, so as to reduce the sales cost of auto insurance, thus making the pricing of auto insurance lower and more attractive. On the other hand, through the analysis of big data and other tools, the calculation of insurance premiums can be more accurate, accurate to every type of users or even every user, making the pricing more reasonable.

Traditional auto insurance sales are not only inefficient but also costly. Traditional auto insurance is mainly sold through $4 \mathrm{~s}$ stores, which need to charge a large commission. And it is likely that a certain insurance company negotiate with the $4 \mathrm{~s}$ store to increase the commission and mainly promote its own auto insurance products, under which circumstance the consumer will bear the increased price ultimately. Selling auto insurance through Internet platforms can save insurance companies a large amount of commission fees, lower surcharges when pricing products, and ultimately benefit consumers.

The traditional auto insurance pricing mainly assumes the accident rate, in which age and gender are the main concerns. When combined with the Internet, it can obtain more abundant and effective data through the big data. For example, OBD hardware equipment can be used to obtain relevant data in the driving process of vehicles, and the data can be processed and analyzed to form available data for insurance pricing, so as to provide insurance companies with more accurate auto insurance pricing and enable each customer to have a good customer experience without complaining about high prices.

\section{B. Problems Existing in Internet Auto Insurance Business}

After the combination of traditional auto insurance and the Internet, there are huge advantages, but at the same time, disadvantages also emerge. The development of Internet informatization has brought great advantages to the Internet auto insurance business, but at the same time, there are also some related problems. For example, online insurance customers may have wrong interpretations of the insurance terms. In addition, it not long since the Internet auto insurance has emerged and thus it is still in a stage of exploration and development. Therefore, the process design of Internet auto insurance is not perfect. Finally, for insurance companies, high-end auto insurance is a high-risk business which requires them to carry out careful underwriting of the insurance subject. Therefore, owners of high-end cars generally don't choose network insurance.

1) Customers have low trust degree of in electronic policy: Internet auto insurance mainly sells through the Internet platform, making the electronization of insurance policies inevitable. However, after consumers purchase auto insurance through the Internet platform, the electronic insurance policies obtained by consumers are kept by insurance companies unilaterally. Will the insurance company make corresponding modifications to the electronic policy in the process of custody? Without the paper policy in hand as proof, consumers may be concerned whether the insurance company will reject claims after the happening of accident. In the case of clause dispute, it will be troublesome for the client to provide proof and will thus 
be faced by loss of interest. Therefore, clients can distrust the electronic policies.

2) The interpretation of terms is prone to deviation: As a kind of contract of adhesion, the clauses of insurance contract are usually stipulated by the insurance company unilaterally, which are the agreement about insurance rights and obligations between insurance company and policyholder. It requires certain specialized knowledge with many item contents. For consumers who do not have any basic insurance knowledge, the interpretation of some exemption clauses and the determination of the warranty time may produce certain discrepancies, which will lay a huge hidden danger for the future insurance contract disputes.

Internet auto insurance is mainly sold through the Internet platform, and there is no special agent to give a detailed explanation in person. And consumers may not read all the terms when they buy insurance on Internet platforms and they may just skim through them. Therefore, there may be some discrepancies in their interpretation of the clauses. At the same time, incompact understanding of the terms will put consumers in a weak position.

3) The process design of Internet auto insurance needs to be improved: Internet auto insurance needs to use the Internet to reform the auto insurance service model and business model by giving to play the innovative spirit of the Internet. The Internet auto insurance business has higher requirements for the internal business process transformation of insurance companies, which requires a set of efficient, reliable and fast information processing systems to ensure that the information of insured customers can be completed in the shortest time from the receiving end to the execution end and errors will be made.

However, for now, the Internet auto insurance is mainly selling through the Internet platform; only small claims can be conducted; and related integration and process design are not perfect enough, with only a small part put on the Internet, instead of the whole.

4) The risk identification ability of Internet auto insurance is weak: In the case of online insurance, it is hard for insurance companies to identify customers' risk profiles. For some high-risk auto insurance businesses, such as the underwriting of high-end models, this will make the insurance company faced with bigger hidden risk. Therefore, at the early stage of the development of Internet auto insurance business, general insurance companies adopted offline insurance for high-end auto insurance. The insurance of high-end cars is a high-risk business for the company. Generally, insurance companies are very cautious in underwriting high-end models, taking into account the moral hazard of customers and other factors to prevent customers from cheating the insurance through the maintenance of high-end models. Therefore, in the case of high-end auto insurance, on-site underwriting is generally carried out, and the customer's previous risk situation needs to be investigated, as well as whether it was personal use or enterprise use or other circumstances. Therefore, customers of high-end models will not choose to insure online, but cover insurance on the spot. After the insurance company understands the relevant situation of high-end cars on the scene, it decides whether to accept insurance or not.

\section{CONCLUSION}

With the increasingly fierce competition of China's auto insurance business and the arrival of the mobile Internet era, no property insurance company will let slip the Internet auto insurance business. Compared with traditional auto insurance business, Internet auto insurance business has the advantages of channel entrance, product pricing and product innovation. However, at present, the development of Internet auto insurance business is still in the early stage, and the auto insurance business has not been deeply integrated with the Internet. Therefore, it is of great significance to analyze the development of Internet auto insurance business.

\section{REFERENCES}

[1] Xu Yinqing, Guo Xing. Research on the construction of WeChat service platform for auto insurance [J]. Shanghai Insurance, 2014(05). (in Chinese)

[2] Hao Yansu. Marketization reform of auto insurance terms and rates in the era of big data and Internet [J]. China Insurance, 2015(04). (in Chinese)

[3] Chen Siming. On the new opportunities for the development of auto insurance business in the "Internet + " era $[\mathrm{J}]$. Journal of Insurance Professional College, 2015(05). (in Chinese)

[4] Cao Yunbo, Jiang Jiaxiang. Opportunities and challenges for professional Internet insurance companies in the era of big data - a case study of "Zhongan Online" [J]. Finance and Accounting Monthly, 2015(08). (in Chinese)

[5] Chen Jin. From "Internet +" to Zhongan +" [J]. China Entrepreneur, 2015(11). (in Chinese)

[6] Wang Jialai. A preliminary study on the whole process network marketing of auto insurance market [J]. World Economic Outlook, 2008(07). (in Chinese) 